\title{
Declaração de Bubaque
}

Alfredo Simão da Silva

O caminho iniciado em Santiago (2007) e que nos trouxe às ilhas Bijagós, começou pela criação de uma estrutura voluntária de pessoas e instituições que tinham como objetivo dar visibilidade às ações de Educação Ambiental nos Países de Língua Portuguesa e Galiza. Esta vontade foi reafirmada no Brasil (2011), com a confirmação da necessidade de reafirmação das distintas realidades, num espaço internacional, a par de outras realidades socioculturais que têm vindo a contribuir de forma crítica para a relevância da Educação Ambiental, enquanto instrumento basilar da construção de uma sociedade sustentável, livre, justa e responsável, tanto à escala local como global.

Desta iniciativa, são hoje parceiros centrais, as comunidades locais com modelos e realidades baseadas em economias sociais e solidárias, processos de auto-organização que contribuem para a redefinição de modelos de desenvolvimento mais resilientes em contexto de alterações climáticas e que são fundamentais para a conservação da biodiversidade e regeneração ambiental, num processo cultural de transição para sociedades ambientalmente mais responsáveis, socialmente justas e equitativas.

A V edição do Congresso sob a temática: "Crise Ecológica e Migrações: leituras e respostas da Educação Ambiental" desafia-nos a pensar alternativas para construir um mundo mais democrático e sociedades mais sustentáveis.

Os participantes do $\mathrm{V}$ Congresso de Educação Ambiental e o povo dos Bijagós reconhecem que o lixo marinho, tema identificado como prioritário no Congresso de Educação Ambiental anterior (2017, Príncipe), bem como pelos Ministros dos Assuntos dos Mares da CPLP (2015, Lisboa; 2016, Díli) continua a ser um dos maiores problemas ambientais que enfrentamos na atualidade, juntamente com as alterações climáticas; identificaram e partilharam iniciativas várias, muitas das quais em Educação Ambiental e com 
o envolvimento direto das comunidades, reconhecendo que o seu impacto precisa ser ampliado.

Tendo-se identificado que a produção de resíduos e a sua falta de tratamento eficaz constituem um problema imediato que precisa ser enfrentado em todos os nossos países, reconhecemos a urgência de se implementarem políticas de Gestão e Educação Ambiental. Este processo precisa considerar a reutilização e a reciclagem dos resíduos (economia circular) e envolver as comunidades pesqueiras; promover a monitorização para melhor compreensão do fenómeno (escalas, origens e impactes ambientais), promover a coordenação das ações, estabelecer parcerias com todos os governos, organizações internacionais, sociedade civil, academia e comunidades locais num compromisso concreto, concertado e continuado no sentido de prevenir e reduzir os impactes do lixo marinho.

Congratulamo-nos com a participação ativa dos jovens da CPLP, bem como com o apoio dado pela UNICEF a esta participação. Fazemos votos e nos mobilizaremos para que a sua participação nos debates para a construção de políticas públicas seja mais efetiva. Nenhuma discussão sobre o futuro que lhes pertence deve ser tomada sem a sua participação.
Ao longo dos debates ficou evidente a expetativa dos participantes, cada vez mais, poderem vir a conhecer as realidades social e ambiental de outros países da CPLP e Galiza, através de programas de mobilidade, proporcionando um maior conhecimento e maior visibilidade das suas políticas, estratégias e planos de Educação Ambiental. Foi, ainda, ressaltada a importância de os participantes do congresso manterem uma vigilância ativa do desenvolvimento da legislação, estratégias e programas de E. A. nos seus respetivos países.

Nas últimas duas décadas, a República da Guiné-Bissau tem investido significativamente na conservação da sua biodiversidade, através da criação de parques nacionais, parques naturais e de áreas marinhas protegidas. Este país enfrenta grandes desafios para garantir que o progresso seja promovido com consciência ambiental e compromisso social. A exemplo da Guiné-Bissau, outros países também possuem uma grande biodiversidade que precisa ser protegida e recuperada. Daí que a conservação e gestão racional dos recursos naturais precise de se constituir como um compromisso de todos, enquanto um legado a deixar às gerações vindouras. A Educação Ambiental é, cada vez mais, uma ferramenta participativa na resolução ou minimização de problemas socioambientais a partir de espaços e 
recursos fora e em complementaridade com o sistema educativo.

Em contextos rurais ou urbanos, os recursos de educação não formal, como os equipamentos para a Educação Ambiental (EqEA) -centros de E.A., museus, centros de interpretação do património, jardins botânicos, os viveiros agroflorestais- estão preparados para funcionar como agentes comunitários na gestão ambiental local, assim como, para oferecer uma leitura sócio crítica e respostas à crise ecológica e social. Os resultados a alcançar serão mais eficientes se houver 0 desenvolvimento de sinergias com redes e equipamentos diversos que integram princípios e compromissos comuns, nomeadamente a rede de volunturismo e a rede das reservas da biosfera que está em formação, nos países de língua portuguesa e galega.

Nos países da CPLP, a Educação Ambiental é consensualmente definida como um instrumento metodológico facilitador e que promove a criação de um novo entendimento no que respeita ao equilíbrio social-económicoambiental. Por um lado, pela valorização dos desejados equilíbrios sociais, económicos e ambientais; por outro, por estimular a criação de emprego e a aquisição de rendimentos, fortalecendo a autonomia, o associativismo comunitário e o empoderamento e, ainda, por potenciar particularidades culturais, referenciais e identitárias centradas no desenvolvimento endógeno numa perspetiva de sustentabilidade. Assim, através da Educação Ambiental, a harmonização da relação entre o desenvolvimento socioeconómico e a valorização ambiental e cultural é conseguida e reforçada.

Os impactos das alterações climáticas traduzem-se em termos de degradação dos ecossistemas; modificação de modos de produção (alterações de práticas agrícolas e de organização dos modos de trabalho), influenciando movimentos migratórios e aumento da pobreza. Este fenómeno que afeta todos os países, precisa de ser enfrentado de forma democrática, equitativa e colaborativa no sentido de reivindicar a justiça ambiental. Por outro lado, a interdependência dos problemas ambientais globais obrigamnos a preparar as nossas comunidades para os riscos e desastres ambientais e saber identificar estas possibilidades e as ações necessárias para mitigar e/ou desenvolver a resiliência comunitária. A Educação Ambiental, tanto ao nível dos sistemas educativos, como em âmbitos não formais, tem que situar a questão climática no cerne da sua agenda. A prioridade será transformar as alterações climáticas, assim como os riscos e desastres ambientais, num problema relevante, significativo e que exige respostas urgentes e articuladas a todos 
os níveis: individual, local, nacional, regional e global.

Este congresso abordou, igualmente, a importância do envolvimento de pessoas com deficiência na área de Educação Ambiental. Os direitos humanos das pessoas com deficiência defendem a verdadeira inclusão, devolvendo-lhes a dignidade e a expressão das suas capacidades/competências que muitas vezes Ihe são negadas, respeitando sempre o perfil de funcionalidade de cada individuo. Esses aspetos convergem com os objetivos da Educação Ambiental que preveem a democracia como forma de garantir sociedades justas e que permitem oportunidades a todos.

Em relação ao sistema educativo, foram apresentadas experiências nos diversos países que tratam das políticas de formação de professores, das práticas pedagógicas em contextos escolares, das temáticas emergentes nos currículos dos diferentes níveis de ensino. Neste contexto, os professores assumem o papel de agentes transformadores ao trabalharem com os seus alunos, esperando que estes repliquem as boas práticas que são trabalhadas nas escolas. No entanto, é possível perceber que ainda precisamos de avançar em relação à inserção da Educação Ambiental nos currículos escolares. Para isto, é preciso criar mecanismos e espaços para a explicitação dos dados estatísticos que se referem aos nossos sistemas de ensino, bem como dar visibilidade aos projetos que têm sido desenvolvidos nas escolas dos países de língua portuguesa e galega.

Cabe-nos, também, a responsabilidade de começar a pensar e a configurar um "currículo de emergência" para os sistemas educativos da CPLP e Galiza e ativar todos os recursos socioeducativos e de comunicação para incentivar as políticas climáticas de adaptação e de mitigação. Cada comunidade, cada região, cada país... terá que desenhar e aplicar as suas respostas educativas perante este desafio, simultaneamente complexo e urgente, na medida das suas possibilidades, responsabilidades e vulnerabilidades. Trata-se de uma questão de justiça ambiental e de sobrevivência humana.

Considera-se de grande importância desenvolver programas de formação para professores e educadores, assim como a disponibilização de recursos pedagógicos, tendo sido uma necessidade identificada.

Por muito tempo, o conhecimento académico imperou na sociedade, numa abordagem hegemónica que negou a emoção, fé ou saberes orais. Contudo, não é mais possível ignorar este vasto conjunto de signos, expressões culturais 
e conhecimentos oriundos das vivências com comunidades tradicionais, povos indígenas ou grupos sociais em situação de vulnerabilidade. Neste congresso, o poder tradicional participou na sua preparação e esteve diretamente envolvido em todo o processo.

Os saberes tradicionais, autóctones, biorregionais, locais, populares ou independentes, trazem contribuições valorosas de diversidade, de complexidade, de cosmovisões e de narrativas que buscam compreender o mundo. Estes conhecimentos constituem-se como contributos relevantes à construção de sociedades sustentáveis, tanto em âmbito local, como regional e mundial.

No mundo contemporâneo, plural e complexo, temos de ter em conta que há várias linguagens de leitura e resposta à crise civilizatória e ambiental que o planeta enfrenta, sendo importante potencializar um espaço e um tempo de discussão, reflexão e propostas que possam trazer contributos ao enfrentamento da crise planetária, em especial aos fluxos migratórios que anunciam um novo patamar de exigência: meios de se conviver, aceitar o diferente, vivenciar os conflitos e buscar construir a solidariedade e os diálogos que incluam todos os saberes às políticas que visem a sustentabilidade planetária.

Por fim, manifestamos aqui a nossa solidariedade em relação ao povo de Moçambique e deixamos aqui registado que assumimos um compromisso na luta para diminuir situações de vulnerabilidade que colocam cada vez mais os nossos países numa situação de fragilidade, a partir das mudanças globais que se anunciam. 